\title{
Jornalismo, noticiabilidade e valores sociais ${ }^{1}$
}

\section{Terezinha Silva e Vera França}

\section{Resumo}

0 artigo discute a problemática dos valores-notícia e da noticiabilidade jornalística no quadro mais amplo dos valores sociais, das relações de poder e do pano de fundo cultural que estruturam uma sociedade. Partimos de uma concepção do jornalismo como atividade comunicacional que se distingue por três eixos: a relação com o real; a natureza do seu produto - a informação; a sua ancoragem no interesse público. Situamos as noções de noticiabilidade e de valores-noticia na articulação desses três aspectos. Propomos discutir tais conceitos a partir do seu vínculo no campo da vida e dos valores sociais. Ao final, exploramos tais questões empiricamente através de análise da cobertura da Operação Lava Jato pela revista Veja.

\section{Palavras-Chave}

Noticiabilidade. Valores sociais. Interesse público. Operação Lava Jato.

Terezinha Silva | terezinhasilva@yahoo.com Doutora em Comunicação pela Universidade Federal de Minas Gerais - UFMG, Brasil, em cotutela pela Université Paris Ouest Nanterre, França. Professora do Departamento de Jornalismo da Universidade Federal de Santa Catarina - UFSC, Brasil.

Vera França I veravfranca@yahoo.com.br Doutora em Ciências Sociais pela Université Paris Sorbonne/ René Descartes, França. Professora Titular do Programa de PósGraduação em Comunicação da Universidade Federal de Minas Gerais - UFMG, Brasil.

\section{Introdução}

A temática que temos estudado ao longo de nossas pesquisas ${ }^{2}$ diz respeito às relações e profundas imbricações entre mídia e vida social, inserindo a produção midiática no âmago da sociedade. Tal perspectiva esvazia indagações sobre 'quem influencia quem', e tanto procura entender o papel e a importância das diferentes mídias na dinâmica da vida social como mostrar o quanto tal dinâmica conforma 0 tipo e 0 desempenho dessas mídias.

No presente texto, nossa reflexão se dirige mais especificamente para o jornalismo, discutindo uma problemática cara às Teorias do Jornalismo (TJ, a partir daqui), que são a noticiabilidade e os valores-notícia. Nosso objetivo é mostrar que tais questões ultrapassam uma economia interna desta prática comunicacional e devem ser vistas à luz das relações de poder e do pano de fundo cultural que estruturam uma dada sociedade em sua trajetória histórica. Mais do que elementos que configuram a linguagem do jornalismo e 0 funcionamento da informação (o que de fato são), 
elas estão inscritas no modelo de sociabilidade e no quadro simbólico que regem a vida social.

Entendemos que o jornalismo é uma atividade comunicacional que se distingue por três eixos:

a) a relação com o real (o jornalismo "fala" a realidade); b) a natureza de seu produto (a informação); c) sua ancoragem no interesse público (ele vai dizer o que, supõe-se, interessa e é pertinente para o grupo ao qual se dirige). Trata-se, naturalmente, de uma dinâmica e uma configuração complexas, e a teorização acerca desses eixos não é consensual. Noticiabilidade e valores-notícia são conceitos que dizem dessa articulação entre fatos da realidade que devem ou merecem ser relatados, devendo ser processados e colocados em circulação na forma de informação, em função de seu possível interesse público.

A discussão desses conceitos tende a ser feita tomando como referência uma pretensa universalidade da forma jornalismo, extraindo-os de sua imbricação no terreno da vida e dos valores sociais. Nossa proposta é promover este resgate, lembrando o quanto o jornalismo, assim como outras práticas comunicacionais, não se auto- explica, mas deve ser compreendido - e ao mesmo tempo nos ajuda a compreender - a própria sociedade (ou alguns de seus grupos) que fala(m) através dele. 0 que nos leva a perceber também que práticas jornalísticas diferentes convivem no seio de uma mesma sociedade.

\section{0 jornalismo}

Como primeiro passo, revisamos rapidamente as características fundantes do Jornalismo enquanto fala (discurso) e prática comunicativa (fazer institucionalizado). A primeira delas, sem dúvida, é sua relação com o reali3: o jornalismo se propõe a falar do mundo em que vivemos em sua dimensão concreta, tangível, partilhada por todos. Trata-se, sem dúvida, de um tema complexo, que recebe vários desdobramentos no seio das TJ, tanto em direção às formas desse dizer (gêneros jornalísticos) como à questão (espinhosa) da verdade.

Não é propósito deste texto fazer uma revisão aprofundada de tais questões, mas tão somente identificá-las naquilo que elas dialogam com nossos propósitos aqui. No que se refere ao gênero (ou gêneros) do jornalismo, uma primeira

Uma primeira versão do texto foi apresentada no XXVI Encontro Anual da Associação Nacional dos Programas de Pós-Graduação em Comunicação (Compós), ocorrido na Faculdade Cásper Líbero, São Paulo - SP, entre 06 a 09 de junho de 2017.0 artigo é resultado de projeto de pesquisa iniciado por Terezinha Silva, em 2016, durante estágio pós-doutoral junto ao GRIS/PPGCOM/ UFMG, sob a supervisão de Vera França. Agradecemos 0 apoio da FAPEMIG e do CNPq, que financiam o projeto GRISLAB (Laboratório de Análise de Acontecimentos), cujas atividades e reflexões colaboram na fundamentação do presente trabalho.

Pesquisas desenvolvidas junto ao GRIS - Grupo de Pesquisa em Imagem e Sociabilidade, criado em 1994, no Departamento de Comunicação Social da UFMG. Acessíveis em http://www.fafich.ufmg.br/gris/

Tomamos aqui o real e a realidade na perspectiva apontada por Berger e Luckman: "uma qualidade pertencente a fenômenos que reconhecemos terem um ser independente de nossa volição (não podemos desejar "que não existam")". (BERGER , LUCKMAN, 1973, p. 11) 
categorização que situa essa prática comunicativa diz respeito à distinção entre linguagem do real e linguagem ficcional. Umberto Eco e Hildegard Feist (2006) falam de uma narrativa natural e uma narrativa artificial; a primeira "descreve fatos que ocorreram na realidade (ou que 0 narrador afirma, mentirosa ou erroneamente, que ocorreram na realidade)" (EC0, 2006, p. 125). Já a narrativa artificial seria "representada pela ficção, que apenas finge dizer a verdade sobre 0 universo real ou afirma dizer a verdade sobre um universo ficcional" (EC0, 2006, p. 126, grifos do autor).

Esta classificação genérica binária é desdobrada de inúmeras formas tanto no terreno da literatura como no campo da mídia e do jornalismo. François Jost (2004), falando sobre gêneros televisivos, apresenta uma divisão tripartite, de acordo com o "tipo" de mundo falado pela linguagem: 0 mundo real, 0 mundo fictício, o mundo lúdico (JOST, 2004, p. 28 e ss.), sendo que a característica do jornal televisivo (e do contrato que estabelece com o telespectador) é "nos informar sobre o nosso mundo [...] ou nos colocar em contato com ele" (JOST, 2004, p. 29).

Já Elisabeth Duarte (2004), num desdobramento da perspectiva de Jost, também apresenta uma classificação a partir da relação entre linguagem e mundo, distinguindo três grandes gêneros: metarealidade (dialogando com o modo informativo); supra-realidade (dialogando com o modo ficcional); para-realidade (dialogando com o modo lúdico).

A linguagem do real, ou natural (o gênero metarealidade, conforme Elizabeth Duarte), não é prerrogativa do jornalismo, mas o inverso é verdadeiro: este deve se colocar, em todas as circunstâncias, em diálogo com o mundo real, falar (d)a realidade. Esta inscrição, no entanto, é apenas a porta de entrada na classificação genérica: a maneira como ele fala desse mundo real abre novas possibilidades de categorização, num contínuo que se estende da descrição objetiva à interpretação, opinião etc.

Para além dos gêneros, uma outra questão se inscreve nesse debate sobre a relação com o real, com os fatos da realidade: a questão da verdade. Terreno espinhoso, como dissemos acima, que situa-se, no que tange ao jornalismo, em torno da noção de objetividade. Houve um tempo em que a linguagem jornalística tinha como meta e padrão alcançar a objetividade absoluta, com a pretensão de traduzir o real sem qualquer interferência de fatores outros (subjetividade do enunciador, interesse político, viés cultural) para além dos aspectos do próprio fato. Essa fase foi razoavelmente superada, porém verdade e veracidade permanecem no horizonte da prática jornalística, conforme lembra Wilson Gomes ${ }^{4}$. 
0 jornalismo é uma atividade integralmente afetada pela norma da veracidade. A notícia, 0 produto específico dessa atividade, ganha em geral a forma verbal de um enunciado declarativo, de uma descrição ou de uma narrativa sobre eventos reais. A opinião e a análise [...] -, subproduto do jornalismo, é também um tipo de ato linguístico essencialmente comprometido com a pretensão de verdade (GOMES, 2009, p. 10-11).

A relação com o real, portanto, coloca-se não apenas como o primeiro distintivo da prática comunicacional jornalística, como também seu grande desafio. Se a pretensa capacidade objetiva de expressar o que as coisas são já foi bastante questionada, permanece o objetivo de buscar a isenção do relato e a explicitação de seu lugar de fala.

0 segundo eixo distintivo do jornalismo (e em íntima conexão com a discussão precedente) é a natureza de seu produto, a sua matéria-prima, que é a informação ou, se pensamos na informação já tratada pelo jornalismo, a notícia. Informação, dito de maneira ampla, remete-se a um elemento novo e caracterizador de uma situação, objeto ou indivíduo; a notícia é o relato dos acontecimentos a partir de uma seleção e ordenação dessas informações, de maneira a produzir sentido.

Notícia e "produção da notícia" constituem um capítulo extenso nas Teorias do Jornalismo, que seria ocioso (e inviável) repertoriar aqui. Interessa apenas enfatizar - num viés que se inspira na perspectiva da construção social da realidade, de Berger e Luckman (1973), e na obra Making
News, de Gaye Tuchman (1978) - que aquilo que se destaca para alguém como acontecimento, os elementos que são identificados enquanto informações relevantes desse acontecimento, e a maneira como tais informações são ordenadas numa narrativa, tomando a forma de uma notícia, fazem parte de um processo que é social, ou seja, são "resultado de um consenso sustentado pelo jogo das interações e das negociações entre parceiros sociais" (MOUILLAUD, 1997, p. 54)

Afastando-nos de um "construcionismo radical", que supõe que tudo é construção, que não existe 0 fato, mas apenas a narrativa do fato, achamos importante, com Louis Quéré (2012), destacar as "duas vidas" do acontecimento: sua dimensão sensível, 0 fato na sua empiricidade que nos atinge e nos afeta (primeira vida); 0 acontecimento enquanto objeto, transformado pela linguagem, simbolizado (segunda vida). Entendemos assim que 0 jornalismo constituiu uma "segunda vida" do acontecimento, construindo a sua narrativa. Não podemos negligenciar a primeira vida do acontecimento, sua existência sensível que afeta, que faz falar. Nem pensar na segunda vida como simples reflexo da materialidade que nos toca, minimizando os enquadramentos, os elementos de inteligibilidade acionados para interpretar os fatos do mundo que, por sua vez, são da ordem da cultura.

A informação enquanto matéria-prima, a notícia enquanto tratamento das informações constituem, portanto, um aspecto central que 
distingue e conforma uma "linguagem" do

jornalismo - destacando que não podemos tomá-

la enquanto dinâmica imanente, mas resultado dos embates do mundo, dos valores culturais, da intersubjetividade construída pela comunidade de jornalistas (TUCHMAN, 1978).

Por fim, como terceiro eixo, o interesse público. Este é usado, lembra-nos Gomes (2009, p. 67 e ss), como o grande esteio do discurso autolegitimador do jornalismo. Para 0 autor, a fundamentação discursiva da legitimidade de qualquer instituição pode ser realizada pelo menos de dois modos: em termos de sua função social (para que serve), ou com base nos valores sociais vigentes (GOMES, 2009, p. 68). Dito de forma sumária, o jornalismo se justifica porque serve ao interesse público, fundamenta a opinião pública, atende ao bem comum. E está em sintonia com os valores democráticos, com a liberdade de opinião, com a realização do debate público ${ }^{5}$.

Mas vale acrescentar ainda a perspectiva de Dewey (2001) para falar de público e de interesse público. 0 ponto de partida do filósofo pragmatista

é o fato objetivo de que ações humanas produzem consequências sobre outros indivíduos, que algumas dessas consequências são percebidas, e que essa percepção leva ao esforço ulterior para controlar a ação de maneira que certas consequências sejam asseguradas e outras, evitadas" (DEWEY, 2001, p. 61).

Quando as consequências se restringem às pessoas diretamente envolvidas na ação, dizemos que elas são privadas; quando elas atingem outras pessoas para além daquelas que as praticaram, e sobretudo se elas "afetam o bem-estar de numerosas outras", dizemos que elas assumem uma dimensão pública. A partir daí "público", para Dewey, diz respeito a uma dada coletividade afetada por uma tal ação ou acontecimento (o público afetado pelo rompimento da barragem da Samarco em Mariana/MG; o público afetado pela eleição de Donald Trump nos Estados Unidos). Interesse público, em decorrência, diz respeito às consequências (desejáveis ou indesejáveis) de certas ações ou acontecimentos que incidem numa sociedade ou parte considerável dela (aos impactos da "primeira vida" do acontecimento).

Por este caminho, poderíamos (ou deveríamos) concluir que o eixo de interesse público a nortear o trabalho jornalístico estaria relacionado, então, às ações e acontecimentos com alto poder de afetação na vida social. A atividade jornalística não se limita, porém, a temas e ações de alto impacto. Isso se pode ver tanto nas notícias sobre a vida das celebridades, o mundo da moda, os esportes etc., quanto em certas temáticas que são

0 jornalismo tal como 0 conhecemos é um produto da modernidade ocidental, e reflete valores iluministas, como assinala Gomes: "as marcas burguesas, liberais e iluministas são de tal maneira essenciais ao discurso de autolegitimação do jornalismo que a esse ponto é impossível separar o mero discurso verbal voltado para mascarar a realidade a partir de um determinado cálculo de ganhos da sinceridade e convicção na adesão ao discurso." (GOMES, op. cit., p. 75) 
assumidas pela mídia e que, em decorrência de sua circulação e repetição, acabam dominando as pautas jornalísticas. Uma rápida observação aos portais de notícias, jornais diários ou telejornais é suficiente para perceber que quase tudo pode se transformar em notícia, assim como nem tudo do que é ali noticiado sequer tangencia o interesse público. 0 que nos levaria à existência de uma diferença e um hiato entre interesse público e interesse $d o$ público, bem como de interesse público e interesse das agências jornalísticas.

Vale dizer brevemente - já que não temos espaço aqui para ir muito longe neste tema - que a grande divulgação midiática é, em si, criadora de acontecimentos, e que tais acontecimentos não são desvestidos de consequências. Eles não impactariam a princípio, mas terminam por impactar pela força de sua divulgação. Esses interesses "outros", que acabam perpassando as práticas do Jornalismo e estabelecendo critérios de noticiabilidade, estão relacionados com valores sociais, com jogo de forças, com tendências e traços culturais. Não há uma regra que permita identificálos a priori; é a análise da cobertura jornalística, do enquadramento que é dado aos acontecimentos, daquilo que se estabelece como notícias e vem estampado nos jornais que nos permite dizer a centralidade dos valores vigentes que edificam os valores-notícia estabelecidos pelas mídias jornalísticas de um determinado país ou região.

\section{Noticiabilidade e valores-notícia}

Somente o suposto interesse público, portanto, é insuficiente para explicar as decisões que levam à definição do que é noticiado e ganha visibilidade nas mídias informativas. Além do interesse público, a noticiabilidade ou os valores-notícia são acionados frequentemente na tentativa de explicar por que certos assuntos são incluídos ou excluídos do noticiário (LARA, 2014). Desde o trabalho pioneiro dos noruegueses Johan Galtung e Mari Huge ([1965]1999), uma corrente forte nos estudos do Jornalismo tem se dedicado à reflexão e/ou à classificação dos valores-notícia ou dos fatores que orientariam os jornalistas no momento de decidir sobre a noticiabilidade de um tema ou acontecimento $0^{6}$.

Partindo da sistematização de vários autores que abordaram o tema, a pesquisadora brasileira Gislene Silva $(2005,2014)$ sustenta que a noticiabilidade está intimamente relacionada, embora não se confunda, com os valores-notícia. Enquanto os valores-notícia são "atributos que orientam principalmente a seleção primária dos fatos" (SILVA, 2005, p.97), a noticiabilidade é um conceito mais amplo, que inclui 0 "conjunto de elementos por meio dos quais a empresa jornalística controla e administra a quantidade e o tipo de acontecimentos", e também "questões ético-epistemológicas" (SILVA, 2005, p.97): 
Noticiabilidade (newsworthiness) [é] todo e qualquer fator potencialmente capaz de agir no processo da produção da notícia, desde características do fato, julgamentos pessoais do jornalista, cultura profissional da categoria, condições favorecedoras ou limitantes da empresa de mídia, qualidade do material (imagem e texto), relação com as fontes e com o público, fatores éticos e ainda circunstâncias históricas, políticas, econômicas e sociais (SILVA, 2005, p. 96).

Não é objetivo deste artigo inventariar as diferentes conceituações e classificações de valores-notícia que supostamente orientariam o processo de seleção e tratamento do que é considerado noticiável pelos agentes jornalísticos? Interessa-nos, sobretudo, indicar certos limites nas formas de abordar a problemática da noticiabilidade e dos valores-notícia. Em tais abordagens, conforme já observado por Leal, Antunes e Vaz (2014, p. 218), esses valores são vistos como "guias que irão orientar os jornalistas na separação dos acontecimentos que são noticiáveis dos demais". Como se os jornalistas tivessem uma "cartela de valores-notícia à mão" ao observar o mundo, selecionando as ocorrências que se encaixam em tais critérios (Lara, 2014, p. 32). A realidade empírica dos acontecimentos e temas priorizados diariamente pelas mídias noticiosas contradizem frequentemente tal concepçãa ${ }^{8}$, indicando, conforme reflexões mais críticas (HARTLEY, 1982; SHOEMAKER, 2006; LARA, 2014), que tais valores podem até ser ferramentas para a leitura dos produtos jornalísticos já publicados, mas não parecem ser as principais balizas a orientar as decisões jornalísticas cotidianas. Ou seja, dizem mais sobre como a cobertura jornalística foi feita do que sobre como os assuntos foram selecionados para a cobertura9 ${ }^{9}$.

Reconhecemos, certamente, a importância do conceito de noticiabilidade e do conhecimento aportado pela pesquisa acerca do tema. Nossa contribuição aqui é no sentido de explorar 0 que entendemos ser uma lacuna nesse campo da pesquisa, ao menos no Brasil. Propomos que os valores sociais e interesses ideológicos - normalmente negligenciados nas reflexões sobre a noticiabilidade - são uma mediação fundamental a ser considerada nas práticas e

Sínteses de outras conceituações e diferentes classificações de valores-notícia em vários autores podem ser encontradas em O'Neill e Harcup (2009); Silva (2005, 2014), Wolf (2001) e Traquina (2005). No que tange às classificações de valores-notícia, a lista inclui, geralmente: 0 inesperado, a relevância, a novidade, a frequência, o conflito, a infração ou desvio; a notoriedade dos atores implicados, a negatividade, a proximidade geográfica e cultural do acontecimento ou tema, dentre outros (GALTUNG;RUGE, 1999; WOLF, 1987; TRAQUINA, 2005).

A título de exemplo, pelo valor-notícia da proximidade (geográfica, cultural), a tragédia provocada pelo rompimento da barragem da Samarco em Mariana/MG teria maior noticiabilidade nas mídias informativas brasileiras do que 0 ataque terrorista a Paris, ocorridos, respectivamente, na primeira e segunda semana de novembro de 2015. Mas não foi o que vimos, já que a cobertura da mídia brasileira ao ataque rapidamente diluiu e quase apagou a cobertura das conseqüências do desastre em Mariana.

Neste sentido, é importante recuperar, com 0’Neill e Harcup (2009), que o estudo pioneiro de Galtung e Huge nos anos 60 não teve a preocupação de identificar valores-notícia. Dedicou-se, na verdade, a criticar a cobertura de três grandes crises estrangeiras na imprensa da Noruega, propondo abordagens alternativas para relatar conflitos. 
processos jornalísticos. Na própria pesquisa internacional em Jornalismo, há estudos que já lançaram intuições profícuas para pensarmos a relação do Jornalismo, suas ações de seleção do noticiável e de construção narrativa com os valores sociais predominantes em um dado contexto socio-cultural. É o caso dos trabalhos seminais de Herbert Gans (1980) e Stuart Hall et al. ([1978]1999) - ambos muito referenciados nas pesquisas da área, mas pouco explorados no que tange à discussão sobre a relação entre a noticiabilidade dos assuntos tratados pelas mídias jornalísticas e os valores sociais ${ }^{10}$.

Em uma pesquisa sobre os conteúdos e 0 funcionamento das redações dos grupos televisivos $C B S$ e $N B C$ e das revistas semanais Times e Newsweek, Gans (1980) identifica e destaca o que ele define como "valores duráveis" na informação, no duplo sentido de normas sociais a respeitar e de instrumentos de cotação e de apresentação da informação. Entendemos que Gans fez um esforço suplementar para além das tradicionais classificações de valores-notícia (importância e interesse do assunto, novidade, qualidade e equilíbrio - conforme a lista proposta pelo autor), que norteariam o processo de escolha por parte de jornalistas e organizações jornalísticas sobre o que é noticiável. 0 sociólogo norte-americano busca situar os agentes jornalísticos e suas escolhas no quadro mais amplo da cultura dos Estados Unidos e o peso que nelas têm certos valores sociais centrais.

Gans (1980) distingue dois tipos de valores, que ele chama de "tópicos" (Topical values) e "duráveis" (Enduring values), sendo estes últimos que ele buscou analisar nas notícias, através de inferências ${ }^{11}$. Assim, valores como o etnocentrismo, a democracia altruista, o capitalismo responsável, a cordialidade da pequena cidade, o individualismo, a moderação, a conveniência de uma dada ordem social e uma liderança nacional capaz de manter tal ordem - identificados e chamados por Gans de "valores duráveis" (1980, p. 38-57) - seriam ferramentas inseparáveis de seleção jornalística dos fatos dignos de atenção e instrumentos de enquadramento da sua cobertura jornalística. Tais valores são incorporados de forma mais regular e frequente pelas notícias. "Eles são incluídos inconscientemente [...], porque eles são construídos em julgamentos de

10 No Brasil, análise recente de Flávia Biroli e Luis Felipe Miguel (2012) recuperam as reflexões de Gans (1980) para propor que a objetividade no Jornalismo e os julgamentos de valor não são excludentes.

11 "Valores tópicos são as opiniões expressas sobre atores ou atividades específicas do momento, seja ele um presidente ou uma nova política contra a inflação", os quais se manifestam nas opiniões explícitas de notícias e nos julgamentos implícitos existentes em todos os relatos. "Valores duradouros, por outro lado, são valores que podem ser encontrados em muitos tipos diferentes de notícias durante um longo período de tempo; freqüentemente, eles afetam quais ocorrências se tornam notícia, pois alguns são parte e parcela da definição de notícia" [...] Eles também ajudam a moldar opiniões, e muitas vezes, as opiniões são apenas especificações de valores duráveis" (GANS, 1980, p. 42 - tradução nossa). 
importância. Como resultado, não conflituam com a objetividade - na verdade, eles a tornam

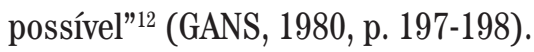

A partir desse enfoque, então, a informação pode ser vista como sendo, em grande medida, uma espécie de prestação de contas dos ataques sofridos por tais valores. Como bem observa Erik Neveu (2004, p. 68), a lista de valores identificados por Gans não é, certamente, exportável e possivelmente precisaria ser atualizada, visto que foi elaborada nos anos 70. No entanto, ela ilustra "a força do laço entre definições jornalísticas do 'valor' de uma informação e a dimensão normativa deste 'valor' quando se trata de definir o enquadramento do acontecimento" (NEVEU, 2004, p. 68).

A noção de enquadramento, portanto, é fundamental quando se discute a relação entre valores sociais tidos como importantes numa sociedade e os processos de seleção e construção jornalística dos acontecimentos. Esse é um dos vazios que percebemos nos estudos sobre a noticiabilidade e os valoresnotícia do Jornalismo, e que acreditamos ser uma das contribuições da presente reflexão. Não se trata aqui, certamente, de uma compreensão de enquadramento como mera escolha individual e/ou técnica por parte dos agentes jornalísticos no momento de construir o seu relato, conforme algumas abordagens na pesquisa da área.
Nossa concepção de enquadramento é inspirada nos "quadros da experiência" (GOFFMAN, 1991) ou "quadros de sentido" (FRANÇA, 2012) que estão na base de uma abordagem - relacional - sobre o processo de enquadramento, o qual é ancorado e orientado por valores sociais e visões de mundo. Em nossa perspectiva, "os quadros são como matrizes interpretativas às quais os indivíduos recorrem cotidianamente para entender e se posicionar em diferentes situações. E 0 'enquadramento' é a mobilização desses quadros - um processo fundamental na organização da experiência" (FRANÇA, SILVA e VAZ, 2014, p. 83), pois permite aos indivíduos definir o que acontece, para se posicionarem e atuarem em determinada situação. Esses quadros são construções socioculturais e não individuais. Eles constituem os elementos centrais de uma cultura, estão sustentados no seu sistema de valores e visão de mundo, são compreendidos pelos membros de uma sociedade e são reafirmados, transformados ou atualizados nas interações e relações sociais (França, Silva e Vaz, 2014), em uma dinâmica na qual as mídias e o Jornalismo desempenham um papel fundamental.

Vemos uma proximidade entre esta noção de quadros de sentido e os "mapas culturais de significado" que o clássico texto de Stuart Hall et al. (1999, p. 226) sustenta ser um elemento fundamental no processo de seleção e construção das notícias. Para os pesquisadores britânicos, 
os valores-notícia são mais do que uma lista de atributos das notícias, combinados e combináveis - que é uma marca de vários estudos sobre 0 tema desde 0 trabalho pioneiro de Galtung $\mathrm{e}$ Ruge (1999) em meados dos anos 60. Segundo Hall et al. (1999), os valores-notícia operam como estrutura de retaguarda social, profunda e escondida, e requerem um conhecimento consensual sobre o mundo. Referindo-se às notícias como uma produção social resultante de vários fatores, eles sublinham a importância dos mapas culturais, mapas de significado ou quadros de referência de fundo (Hall et al., 1999), no momento da construção das notícias, os quais são compartilhados pelos agentes jornalísticos e seus públicos, pois sem eles a comunicação e a produção de sentido sobre os acontecimentos seriam impossíveis.

Tal reflexão destaca, portanto, que a origem dos valores-notícia é mais complexa e diversa do que a normalmente tratada na pesquisa da área, remetendo à dimensão do simbólico, da ideologia e dos processos de representação - os quais, é importante ressaltar, são alimentados e sustentados por valores sociais. Hall e seus colegas de pesquisa estão atentos ao papel das mídias na reprodução da "ideologia dominante" e na sua atuação, mesmo involuntariamente, no processo de controle social. Tais processos são, certamente, complexos. Mas entendemos que estes pesquisadores sinalizam para a existência, nos processos e narrativas jornalísticas, de uma profunda imbricação dos agentes jornalísticos e os chamados valores-notícia com a sociedade - com os valores dos públicos e as expectativas sobre 0 que seria a normalidade da vida social. 0s "mapas de significado" incorporam e refletem os valores comuns, formam a base dos conhecimentos culturais e são mobilizados no processo de tornar um acontecimento inteligivel aos públicos das mídias.

Em resumo, os valores-notícia são definidos contextualmente, e possuem um vínculo profundo com os valores sociais e com a ideologia.

Se pensarmos o Jornalismo não como mera transmissão de informações e sim como parte de um processo comunicativo em que há diferentes sujeitos em interação, conforme o paradigma relacional (FRANÇA, 2006), podemos compreender que os atores do campo jornalístico (jornalistas, organizações midiáticas etc) têm um forte laço com a cultura e a sociedade com a qual se comunicam, sobre a qual falam, conflituam ou compartilham perspectivas e valores sociais. Estas visões e valores comuns também alimentam e orientam a cultura profissional e organizacional do Jornalismo, sendo, assim, uma importante mediação a estimular ou constranger suas práticas, seus critérios de decisão, suas interpretações e suas narrativas. Podemos dizer que entre as mídias jornalísticas e a sociedade há uma "dinâmica de reflexividade: os meios de comunicação 'falam' de (refletem) uma sociedade, assim como sua contínua produção discursiva, e a circulação e renovação de representações proporcionadas pela mídia repercutem e atuam 
na conformação da vida social" (FRANÇA, 2012, p. 8). Por esta via, então, é plausível pensar que os critérios de escolha dos agentes jornalísticos também são orientados por valores sociais que, ao mesmo tempo, através de suas narrativas, são reafirmados, questionados ou atualizados.

Se a noticiabilidade refere-se ao conjunto dos fatores que condicionam as escolhas do que se tornará (e como se tornará) notícia, e se, conforme argumentamos aqui, valores sociais e ideologia edificam os valores-notícia a partir dos quais os agentes jornalísticos recortam os fatos noticiados, que tipo de interesses portam as notícias? Tratarse-ia de interesse público? 0 que tais interesses expressam? 0 que revelam acerca do que a sociedade (ou grupos sociais específicos) valoram na atualidade? Tratamos de abordar essas questões, na sequência, a partir de uma análise da cobertura da Operação Lava Jato pela revista Veja.

\section{O valor-notícia da Lava Jato para a revista Veja}

Para explorar nosso argumento acerca da relação do Jornalismo com os valores sociais, e da importância de considerá-los uma mediação fundamental nos estudos sobre a seleção e interpretação do que é noticiável, realizamos um ensaio analítico em torno da cobertura da
Operação Lava Jato pela revista Veja, durante 0 ano de 2016. A Lava Jato (LJ) foi deflagrada em 17 de março de 2014 (1ªse), com a prisão preventiva de dezenas de pessoas, dentre as quais o doleiro Alberto Youssef. A partir das chamadas "delações premiadas" de Youssef, nos meses seguintes a $L J$ tornou-se tema recorrente da agenda público-midiática e da cobertura jornalística no Brasil e no exterior, e uma espécie de referência do combate à corrupção no Brasil atual ${ }^{13}$. Em 2016, ano em que as atividades da Lava Jato desempenharam um papel importante no contexto do golpe que derrubou a presidenta Dilma Rousseff - como o vazamento ilegal, pelo juiz Sérgio Moro, das escutas telefônicas de diálogo entre a presidenta e 0 ex-presidente Luiz Inácio Lula da Silva -, a revista Veja foi a mídia que mais falou sobre assuntos relativos a esta Operação, segundo o monitoramento de mídia realizado pelo Laboratório de Análise de Acontecimentos (GrisLab/UFMG) ${ }^{14}$.

Nossa análise aqui apoia-se nos dados extraídos deste monitoramento do Radar do GrisLab. 0 Radar do GrisLab monitorou, ao longo de 2016, os principais acontecimentos repercutidos em portais de notícia e revistas, totalizando nove mídias informativas, acessíveis via internet e de diferentes linhas político-editoriais: os portais UOL, Globo.com, Terra e R7, e as revistas Fórum,

13 Em agosto de 2017, a Operação Lava Jato estava em sua 45a fase.

140 GrisLab é um projeto de pesquisa e extensão, iniciado em junho de 2013 pelo Grupo de Pesquisa em Imagem e Sociabilidade (GRIS/PPGCOM/UFMG). 
Carta Capital, Veja, Istoé e Época ${ }^{15}$. Em termos quantitativos, os dados do Radar mostram que a Lava Jato teve uma significativa cobertura destas mídias ao longo de 2016, totalizando 861 matérias ${ }^{16}$. Na análise mês a mês, a Lava Jato só não ocupou o primeiro lugar entre os 10 principais assuntos destacados no Radar nos meses de janeiro (assuntos relativos à economia), abril (impeachment da presidenta Dilma), maio (governo Temer), agosto (Olimpíadas) e novembro (eleições presidenciais nos EUA). Dentre as mídias monitoradas, a revista Veja foi a que mais tratou da Lava Jato, com 146 matérias ao longo do ano ${ }^{17}$. Em seguida, aparece as revistas Istoé, com 124 textos, e Época, 122; os portais G1, com 100; UOL, 90; R7, com 87; e Terra, 63; a revista Carta Capital, com 52; e o Estadão, com $42^{18}$.

Por que a Lava Jato teria sido tão importante? 0 que essa cobertura estava revelando? 0 combate à corrupção (probidade) é um grande valor em nossa sociedade?
Para o presente ensaio analítico, realizamos uma pesquisa exploratória tendo como base o universo de 146 matérias veiculadas pela revista Veja em 2016 e capturadas pelo Radar do GrisLab. Considerando a amplitude desse universo e os limites do presente artigo, optamos por fazer um recorte temporal compreendendo apenas o primeiro semestre de 2016, limitando nossa análise somente aos títulos das matérias publicadas. Nosso corpus foi composto, assim, por 93 textos veiculados por Veja entre janeiro e junho de 2016. Títulos são uma proposição geral de sentido, que sintetizam a ideia mais ampla contida na informação noticiada. Como diz Mouillaud (1997), o título extrai algo de nuclear na notícia e, simultaneamente, reduz e simplifica as informações, interpreta 0 texto, dirige 0 entendimento do público sobre a notícia, mostrando, na prática, como o veículo posicionase sobre 0 assunto; é opinião disfarçada de emissão neutra. Por essas características, acreditamos que a análise dos títulos é adequada para o objetivo proposto aqui de explorar a

150 monitoramento feito pelo Radar do GrisLab, é realizado a partir das manchetes disponibilizadas nos sites do UOL, Globo.com, Terra, R7, além das revistas Forum, Carta Capital, Veja, Istoé e Época. De segunda a sexta-feira, a equipe do GrisLab realiza três acessos diários - manhã, tarde e noite -aos sites destes veículos e coleta a manchete que está em destaque naquele período. Os temas encontrados e os respectivos links dos textos são armazenados numa planilha. A cada mês, a equipe faz um relatório daquilo que o Radar capturou no período, classificando os 10 assuntos mais destacados nas mídias monitoradas. Todos os dados estão acessiveis em: http://grislab.com.br/grislab-radar/

16 A frequência foi assim distribuída: em janeiro, 57 matérias; fevereiro, 90; março, 180; abril, 58; maio, 32; junho, 105; julho, 64; agosto, 21; setembro, 104; outubro, 79; novembro, 23; e dezembro, 44.

17 Pelo nosso corpus, ao longo de 2016 a Lava Jato foi 0 assunto mais abordado por Veja nos meses de janeiro, fevereiro, março, junho, julho, setembro, outubro e dezembro; ficou em segundo lugar em abril (impeachment) e novembro (eleição nos EUA), terceiro em maio, e quarto lugar em agosto (olimpíadas, impeachment e eleições municipais respectivamente).

18 Por alterações na metodologia de coleta do Radar do GrisLab, não foram monitorados ao longo de todo 02016 a revista Fórum (somente a partir de junho) e o Estadão (incluído apenas até maio). 
relação entre 0 valor de notícia atribuído a fatos e acontecimentos que ocuparão o espaço midiático e valores sociais, relações de poder, ideologia ${ }^{19}$.

A leitura dos títulos das 93 matérias de Veja nos permitiu reconstruir (projetar) a narrativa construída pela revista ao longo desses meses acerca da Lava Jato; para isto buscamos identificar o agente da ação, a ação e o objeto da ação. 0 enredo dessa narrativa nos dá indícios dos posicionamentos e valores que impulsionaram a(s) ênfase(s) da revista.

Um elemento-chave no tratamento dado por Veja diz respeito aos atores que a revista traz para compor a sua narrativa sobre a Operação Lava Jato, a qual também denomina de "petrolão" ou "escândalo do petrolão". Tais atores são majoritariamente nomes do PT e outros tidos como aliados do governo de Dilma Rousseff, além de integrantes do Judiciário no papel de investigadores e/ou de juízes. 0 ex-presidente Lula é o mais citado. Na contabilização dos títulos dos 93 relatos jornalísticos, Lula é o personagem central em 30 deles, seguido pela presidenta Dilma
(12), o marqueteiro do PT João Santana e a esposa Mônica Moura (10); o juiz Sérgio Moro (09); e o procurador da República, Rodrigo Janot (06), dentre os mais citados ${ }^{20}$.

Tal ênfase em Lula (presente em 30 títulos) encontraria justificativa na lista de critérios normalmente apontados como geradores de valor-notícia? 0 critério de "notoriedade" dos personagens envolvidos em um acontecimento sem dúvida é importante - e 0 ex-presidente é certamente uma figura notória. Mas, naquele momento, ele não era mais o chefe do Executivo, 0 chefe do partido, e tampouco os fatos comprovavam (embora insistentemente se tenha buscado fazê-lo) o "chefe da quadrilha". Então em princípio ele não era, nesse episódio, tão notório assim. Por que Veja insistia em darlhe tanta ênfase? E o que a revista destacava de tal personagem que seria tão decisivo na noticiabilidade do fato? ${ }^{21}$

Na construção narrativa de Veja, Lula é representado como "suspeito" - de encobrir propinas com palestras, de receber vantagens

190 detalhamento de como uma determinada mídia aborda a questão de fundo tematizada em sua narrativa (no caso da Lava Jato, a corrupção), possíveis oscilações ou dissonâncias no tratamento do tema e de atores implicados, ou mesmo possibilidades de disputas de enquadramentos e questionamentos de valores no interior da própria narrativa daquela mídia, demandaria, certamente, outros procedimentos metodológicos para além da análise dos títulos dos textos (a íntegra das reportagens, as fotos e legendas, subtítulos, chamadas de capa etc) e do período de seis meses.

20 Estão também entre os mais mencionados: os senadores Collor de Melo (04); Delcídio Amaral (04) e Renan Calheiros (02); 0 ex-diretor da Petrobrás Nestor Cerveró (04) e da Transpetro Sérgio Machado (02) ; o presidente da Câmara Eduardo Cunha (04); 0 ex-ministro José Dirceu (03), o ministro Jacques Wagner (02), o ministro do STF e relator do processo da Lava Jato, Teori Zavascky (02).

21 Se incluímos, além de Lula, Dilma e outras pessoas ligadas ao PT, vemos que estão presentes em 81 títulos dos 93 textos de nosso corpus. 
indevidas durante 0 mandato, através das quais teria conseguido a propriedade (por ele ocultada) de um apartamento triplex no Guarujá e um sítio em Atibaia (SP). "Denunciado" no caso do sítio, Lula é também quem deu apoio político a Nestor Cerveró para a diretoria da Petrobrás e quem "deu a benção a empréstimo fraudulento e contrato bilionário" com a estatal. É alguém que "resiste" ao ser chamado para depor com sua família e que "ataca" o juiz Sérgio Moro. Convoca os petistas para sair às ruas, definindo-se como uma "jararaca" que ainda está viva, faz articulações para ganhar um ministério no governo Dilma e assim se proteger contra o juiz Sérgio Moro. Pediu a intervenção do Palácio do Planalto no Supremo Tribunal Federal (STF) e tem um plano secreto de fugir para a Itália após a Justiça de São Paulo encaminhar o pedido de sua prisão ao juiz Sérgio Moro ${ }^{22}$.

Todos os demais personagens que aparecem nos títulos têm menos da metade do número de citações de Lula. E o segundo nome mais mencionado é Dilma Rousseff (12 citações ${ }^{23}$. Como presidente em exercício, tem uma notoriedade óbvia - embora não tão óbvia no quadro do acontecimento. A construção de Veja descreve-a como uma presidente sem firmeza, pois cede a nomeações e não argumenta. Teria favorecido Collor de Melo, é interpelada sobre suas viagens e teve sua campanha de 2014 colocada sob suspeita a partir da prisão de seu marqueteiro, João Santana e da esposa, Mônica Moura, tornados "réus" no âmbito das investigações da Lava Jato. No relato de Veja, a presidenta também sabia da compra superfaturada de Pasadena e atuou para evitar a prisão de Lula, buscando garantir a posse dele como ministro de seu governo. Pelos atributos e ações que lhe imputa, Veja parece reservar a Dilma um papel secundário no enredo da Lava Jato se comparado ao que é atribuído a Lula, seja pelo rol dos feitos de cada um que são colocados em suspeição, seja pela situação de embate em que posiciona o ex-presidente com outra personagem central, o juiz Sérgio Moro.

Vale destacar a importância que a revista investe no marqueteiro João Santana e sua esposa (10 citações); seu valor-notícia não está no papel e na importância intrínseca do casal, mas em sua relação com a campanha presidencial de 2014.

22 Ver, por exemplo: PF diz ter "alto grau de suspeita" sobre tríplex de Lula no Guarujá (Veja, 27/01/2016); Lava Jato investiga Lula por suspeita de vantagens indevidas durante o mandato (Veja, 29/02/2016); Ministério Público marca depoimento de Lula, Marisa e Lulinha para próxima quinta (Veja, 26/02/2016) ; STF nega pedido para parar investigações contra Lula e Lula ataca Moro e chama petistas às ruas: 'A jararaca está viva' (Veja, 04/03/2016) ; Ministério Público de SP pede prisão preventiva de Lula (Veja, 10/03/2016); Lula tem plano secreto para evitar prisão: pedir asilo à Itália (Veja, 24/03/2016); Executivos reafirmam 'bênção' de Lula a empréstimo fraudulento e contrato bilionário com a Petrobras (Veja, 20/04/2016); Justiça de SP envia a Moro pedido de prisão de Lula (Veja, 02/05/2016); Lula vira réu por tentar obstruir a Operação Lava Jato (Veja, 29/07/2017). Disponíveis em: http://grislab.com.br/grislab-radar/page/2/ e em http://veja.abril.com.br

23 Ver, por exemplo: Após delação de Delcídio, MP discute investigar Dilma e Lula na Lava Jato (Veja, 15/03/2016); Grampos indicam que Dilma agiu para tentar evitar prisão de Lula; Janot vai abrir inquérito contra Dilma (Veja, 16/03/2016); STF inclui menções a Dilma, Lula e Temer em inquérito da Lava Jato (Veja, 20/04/2016); Dilma mentiu sobre Pasadena, diz Cerveró (Veja, 02/06/2016). Disponíveis em: http://grislab.com.br/grislab-radar/page/2/ e em http://veja.abril.com.br 
Ou seja, eles apenas se mostram decisivos para deslindar as investigações na medida de seu envolvimento com petistas ${ }^{24}$.

0 juiz Moro, terceiro na sequência (09 citações), está longe da ênfase dada a Lula - mas vale lembrar o papel que lhe é reservado na narrativa de Veja. É um juiz guiado por princípios nobres, cujas ações no âmbito da Lava Jato colocaramno entre as 50 personalidades mais influentes do mundo no ranking da revista Fortune. Moro luta contra a impunidade no Brasil, um dos motivos pelos quais defende a condenação de réus em segunda instância. Foi atacado por Lula em discurso. Pediu desculpas ao Supremo Tribunal Federal pela "polêmica dos grampos" telefônicos entre a presidenta Dilma e o ex-presidente Lula, mas negou que a divulgação das escutas tivesse finalidade política. Teve a ação dos grampos anulada pelo STF, mas, em compensação, recebeu do Supremo as investigações contra 0 expresidente Lula, o que lhe dá o poder de decidir sobre sua possível condenação e prisã $0^{25}$.
Outros atores são trazidos por Veja para compor a sua narrativa do que nomeia de "petrolão" Esses personagens, porém, parecem ter um papel figurante na construção do "escândalo do petrolão" da revista. Por um lado, reforçam 0 enredo no qual a figura central é o ex-presidente Lula - 0 suspeito de construir patrimônio privado (tríplex no Guarujá; sítio em Atibaia) através de benesses de empreiteiros(as) investigados pela Lava Jato -, e que terá que enfrentar o temido juiz Sérgio Moro, espécie de herói do combate à corrupção e à impunidade. Por outro lado, alguns figurantes do relato de Veja (Eduardo Cunha, Aécio Neves, Michel Temer) ${ }^{27}$ parecem também cumprir a função de acrescentar certa diversidade de atores na suspeição que Veja lança sobre os políticos e suas práticas - uma espécie de estratégia de equilíbrio no tratamento dado ao tema.

\section{Considerações finais}

Ao final de nosso percurso cabe resgatar alguns aspectos, buscando compreender melhor as

24 Ver, por exemplo: Alvo da Operação Lava Jato, marqueteiro do PT chega ao Brasil (Veja, 23/02/2016) ; João Santana e Mônica Moura viram réus na Lava Jato (Veja, 29/04/2016); Marqueteiro de Dilma admite que recebeu US\$ 4,5 mi de caixa 2 (Veja, 21/07/2016). Disponíveis em: http://grislab.com.br/grislab-radar/page/2/ e em http://veja.abril.com.br

5 Ver, por exemplo: Lula ataca Moro e chama petistas às ruas: 'A jararaca está viva' ( Veja, 04/03/2016); Para tirar Lula das mãos de Moro, PT pressiona ex-presidente a assumir ministério (Veja, 09/03/2016) ; Moro entra para o ranking dos 50 maiores líderes mundiais da 'Fortune' (Veja, 24/03/2016); Moro pede desculpas ao STF por "polêmica" de grampo e nega que divulgação teve finalidade Política (Veja, 29/03/2016). Disponíveis em: http://grislab.com.br/grislab-radar/page/2/ e em http:// veja.abril.com.br

26 Tratam-se de delatores ou depoentes, como diretores da Petrobrás, empreiteiros ou outros empresários, senadores e procuradores, ministros e ex-ministros ligados ao PT e/ou PMDB.

27 Ver, por exemplo: Por unanimidade, STF coloca Cunha no banco dos réus (Veja, 04/03/2016); Para salvar Cunha, assinatura de deputado do Conselho de Ética foi falsificada (Veja, 09/03/2016); STF inclui menções a Dilma, Lula e Temer em inquérito da Lava Jato (Veja, 20/04/2016); Janot pede depoimento de Aécio em investigação sobre Furnas em até 90 dias (Veja, 02/05/2016); Temer eleva o tom e diz que acusações de Machado são "levianas e criminosas" (Veja, 16/06/2016). 
fontes do valor que a revista Veja atribui a (determinados) assuntos e atores relacionados às investigações da Lava Jato. Sem dúvida, a ênfase à Operação, seu alto grau de noticiabilidade na imprensa brasileira é claramente justificável. Trata-se de um acontecimento que afeta e diz respeito a um problema público crônico na sociedade brasileira, que é a corrupção. E mais: iniciar uma investigação prolongada, tocando notáveis, e romper de alguma forma a impunidade é uma novidade em terras brasileiras. Chama a atenção, no entanto, o fato de que 0 tema recebe em Veja um espaço maior que nas demais publicações pesquisadas, e uma ênfase significativa face a outros temas tratados pela revista no mesmo período.

Além disto, o tipo de enquadramento evidencia um posicionamento muito claro de Veja: a proporção tomada pela Lava Jato recai sobre determinados atores e suas ações e não sobre outros. Embora o trabalho de seleção seja inerente à atividade jornalística, a análise deixa evidente a ênfase dada pela revista a atores governistas, sobretudo petistas, tanto em termos quantitativos quanto na representação que constrói dos atores e suas práticas - visível mesmo na análise focada apenas nos títulos dos textos jornalísticos do corpus.

0 ex-presidente Lula e a presidenta Dilma são certamente figuras públicas notáveis, cujas ações têm natural interesse para as mídias jornalísticas (e seus públicos). Da mesma forma, pela abordagem convencional da noticiabilidade e pelo princípio jornalístico de defesa do interesse público, seriam igualmente noticiáveis as práticas do principal líder da oposição, Aécio Neves, dos presidentes da Câmara dos Deputados, Eduardo Cunha, e do Senado, Renan Calheiros, e do vicepresidente da República Michel Temer. Uma transgressão às normas e à falta de probidade na gestão público-política por parte de qualquer um deles afetam, a princípio, o interesse público e se apoiam em "valores duráveis" (Gans, 1980). № entanto, o enquadramento tendencioso (ênfase em alguns, acobertamento de outros) mostra que valores tópicos, situados em um determinado contexto político e referidos a determinados grupos, intercedem mais que 0 valor durável (combate à corrupção e à improbidade administrativa).

A retórica de Veja sugere a defesa do interesse público, atribuindo alta noticiabilidade a atividades da Lava Jato, mas a sua cobertura do tema revela, na verdade, que esse valor político (interesse público) é mobilizado pelo discurso da revista muito mais para a destruição simbólica de certos atores e agendas do que para promover uma discussão pública esclarecida sobre 0 combate à corrupção. Em outras palavras, a defesa do valor durável serve apenas de pano de fundo para sustentar o valor tópico que orienta a campanha levada a cabo pela revista há muitos anos. Entendemos que a Lava Jato tem grande valor-notícia para Veja porque as atividades da Operação permitem a revista atuar na defesa de sua perspectiva ideológica (combate a Lula, ao PT e agendas políticas a eles relacionadas). 
Veja, porém, não segue seus valores próprios sem respaldo ou reconhecimento de seu público. Entre a revista e seus leitores há um horizonte comum de valores e visões de mundo, que se reafirmam, atualizam-se na maneira como a revista realiza a sua cobertura, posiciona-se, seleciona e enquadra temas, representa os atores.

Não é novidade dizer que uma publicação fala para um público específico, respaldada pelo partilhamento de valores e horizontes de expectativa. Mas uma revista também "cria" seu público pela afetação que produz, alimentando e configurando seus leitores. Um acontecimento, sabemos, produz consequências e suscita significados. Consideramos que a existência da Lava Jato, enquanto acontecimento existencial (primeira vida) impacta a sociedade. Uma força-tarefa de investigação está identificando desvios de dinheiro público, prendendo figuras importantes do cenário político e econômico do país, interferindo no quadro político, institucional e no desenvolvimento econômico. Mas os autos da investigação, os depoimentos, a realidade das prisões, estão distantes, e a eles só temos acesso através de narrativas. Nessa segunda vida, criada por Veja (nosso objeto empírico aqui), há um personagem central, comandando uma rede, patrocinando um assalto ao país. Essa rede do mal está instalada no governo. 0 acontecimento, em sua primeira e segunda vidas, desdobra-se em novos acontecimentos, produz consequências.
Não por acaso a cobertura da revista recrudesceu no mês de março de 2016, paralelamente às manifestações que sustentaram o início do processo de impeachment de Dilma Rousseff, em abril, e culminaram na aprovação do afastamento da presidenta eleita e na consumação do golpe, em agosto de 2016.

Como último ponto, e fechando nosso trabalho, gostaríamos apenas de ressaltar que nossa leitura destacou elementos que são claramente perceptíveis por qualquer leitor crítico (a tendenciosidade de Veja). Nosso objetivo, mais do que reforçar essa denúncia, procura chamar a atenção para as complexas dinâmicas simbólicas que permeiam as relações de força entre grupos da sociedade e se traduzem nas práticas jornalísticas e comunicacionais.

Como propomos aqui, apoiando-nos nas reflexões de Gans (1980) e Hall et. al (1999), valores sociais são uma mediação importante no processo de definição, seleção e interpretação de temas e acontecimentos considerados noticiáveis pelos agentes jornalísticos; "valores-notícia" do jornalismo se apoiam em uma profunda retaguarda social e requerem um conhecimento consensual sobre o mundo. 0s "mapas culturais de significado" (ou quadros de referência e de sentido), que incorporam e refletem os valores comuns, são compartilhados pelos agentes jornalísticos e seus públicos, e são mobilizados no processo de definição e contextualização de um acontecimento, de forma a torná-lo inteligível aos públicos. 
Defendemos que a origem dos valores-notícia está inscrita na dimensão do simbólico, da ideologia e dos processos de representação - os quais são alimentados e sustentados por valores sociais e interesses estabelecidos. Ou seja, os valores-notícia do jornalismo são definidos contextualmente e têm como pano de fundo um denso vínculo com a ideologia e com os valores vigentes na sociedade, com a forma como seus grupos específicos representam o mundo social e com aquilo que eles valoram em um determinado momento histórico. Portanto, não se fazem Teorias do Jornalismo fora de uma boa reflexão sobre as relações entre sociedade e comunicação. $0 u$ seja, externa a uma análise comunicacional.

\section{Referências}

BERGER, Peter L., LUCKMANN, Thomas. A construção social da realidade. 6a. Ed. Petrópolis: Vozes, 1985.

BIROLI, Flávia; MIGUEL, Luis Felipe. Orgulho e preconceito: a objetividade como mediação no jornalismo. In: Opinião Pública, Campinas, Vol. 18, N. 01, pp. 22-43, Junho/2012. Disponível em: http:// periodicos.sbu.unicamp.br/ojs/index.php/op/article/ view/8641396. Acesso: 10/12/2016.

DEWEY, John. Le public et ses problèmes. Extrait de The public and its problemas [1927]. Trad. Joelle Zask. In: LOpinion Publique. Perspectives anglo-saxonnes. Hermès, 31. Ed CNRS. Paris, 2001, pp. 77-91.

DUARTE, Elisabeth Bastos. Televisão. Ensaios metodológicos. Porto Alegre: Sulina, 2004.

EC0, Umberto; FEIST, Hildegard. Seis passeios pelos bosques da ficção. São Paulo: Cia. das Letras, 2006.

FRANÇA, Vera R.V. Sujeito da comunicação, sujeitos em comunicação. In: GUIMARÃES, C.; FRANÇA, V. (Org.).
Na mídia, na rua: narrativas do cotidiano. 1ed. Belo Horizonte: Autêntica, 2006, v. 1, p.61-88.

FRANÇA, Vera R.V.; SILVA, Terezinha; VAZ, Geraldo Frances Fonseca. Enquadramento (Verbete). In: FRANÇA, Vera R.V; MARTINS, Bruno Guimarães.; MENDES, André Melo (Org.). Grupo de Pesquisa em Imagem e Sociabilidade (GRIS): trajetória, conceitos e pesquisa em Comunicação. 1ed. Belo Horizonte: PPGCOM-UFMG, 2014, v. 1, p. 82-85.

GALTUNG, Johan e RUGE, Mari Holmboe. A estrutura do noticiário estrangeiro - a apresentação das crises do Congo, Cuba e Chipre em quatro jornais estrangeiros. In: TRAQUINA, N. (Org.). Jornalismo: questões, teorias e 'estórias'. Comunicação \& Linguagens. Veja, $2^{\mathrm{a}}$ edição, 1999. pp.61-73.

GANS, Herbert. Deciding what's news. Vintage, New York, 1980.

GOFFMAN, Erving. Les cadres de l'experience. Paris. Les Éditions de Minuit. 1991.

GOMES, Wilson. Jornalismo, fatos e interesses. Ensaios de teoria do jornalismo. Florianópolis: Insular, 2009.

HALL, Stuart et al. ([1978], 1999). A produção social das notícias : 0 'mugging' nos media. In: TRAQUINA, N. (Org.). Jornalismo: questões, teorias e 'estórias'. Comunicação \& Linguagens. Veja, 2a edição, 1999. p.223-248.

LARA, Eliziane. Quem faz a agenda? In: LEAL, B. S.; ANTUNES, E.; Vaz, P. B. (Org.) Para entender o jornalismo. Ed. Autêntica. Série comunicação. 2014. p. $29-40$.

MOUILLAUD, Maurice. A crítica do acontecimento ou 0 fato em questão. In: MOUILLAUD, Maurice, e PORTO, Sérgio (Orgs.). 0 jornal - da forma ao sentido. Brasília: Ed. Universidade de Brasílias, 1997, p.49-83.

NEVEU, Erik. Sociologie du Journalisme. Éditions La Decouverte, Paris, 2004. 
0'NEILL, Deirdre; HARCUP, Tony. News Values and Selectivity. In: WAHL-JORGENSON, Karin; HANISTZSCH, Thomas. The handbook of journalism studies. ICA handbook series. Routledge, New York, 2009. p 161-174. Disponível em: http://www. rasaneh.org/Images/News/AtachFile/30-9-1390/ FILE634600594129473750.pdf. Acesso: 13/01/2017. QUÉRÉ, Louis. A dupla vida do acontecimento. Por um realismo pragmatista. In: FRANÇA, Vera R.V., OLIVEIRA, Luciana (orgs). Acontecimento: reverberações. Belo Horizonte: Autêntica, 2012.

SILVA, Gislene. Para pensar critérios de noticiabilidade. In: Estudos em Jornalismo e Mídia, Vol II, $\mathrm{N}^{0} .1$ $1^{0}$. Semestre 2005, p. 95-107. Disponível em: https:// periodicos.ufsc.br/index.php/jornalismo/article/ viewFile/2091/1830. Acesso: 10/01/2017.

SILVA, Gislene. Para pensar critérios de noticiabilidade. In: SILVA, Gislene; SILVA, Marcos Paulo da; FERNANDES, Mario Luiz. (Org.) Critérios de noticiabilidade: problemas conceituais e aplicações. Florianópolis: Insular, 2014.

SHOEMAKER, Pamela J. News and newsworthinesss: a commentary. 2006. Disponível em: http:// jonathanstray.com/papers/News.

SHOEMAKER, Pamela J.; REESE, Stephen. Mediating the message: theories of influences on mass media content. New York: Longman, 1996.

TRAQUINA, Nelson. Teorias do Jornalismo. Volume II. A tribo jornalística - uma comunidade interpretativa transnacional. Ed. Insular. Florianópolis/SC, 2005.

TUCHMAN, GAYE. Making News. A study in the construction of reality. New York: Free Press, 1978. 


\begin{tabular}{|c|c|}
\hline $\begin{array}{l}\text { Journalism, newsthworthiness } \\
\text { and social values }\end{array}$ & $\begin{array}{l}\text { Periodismo, noticiabilidad } \\
\text { y valores sociales }\end{array}$ \\
\hline $\begin{array}{l}\text { Abstract } \\
\text { This article aims to discuss the problem of values- } \\
\text { news and newsthworthiness in a wider frame of } \\
\text { social values, power relationships and cultural } \\
\text { background, all this, as structural factors in } \\
\text { society. Our rationale is a journalist conception as } \\
\text { discourse and communicational practice that can } \\
\text { be distinguished by three axes: the relation with the } \\
\text { real; the nature of its product - the information; } \\
\text { its anchoring in the public interest. We entangled } \\
\text { notions of newsworthines and values-news in these } \\
\text { three axes. Our scope is to discuss such concepts in } \\
\text { the point of view of its embeddedness in the field of } \\
\text { values and social life. We have studied empirically } \\
\text { these issues through an analysis of journalist } \\
\text { covering, by Veja magazine, on the most important } \\
\text { criminal prosecution in Brazil, named "Lava Jato". } \\
\text { Keywords } \\
\text { Newsworthiness. Social values. Public interes. } \\
\text { "Lava Jato". }\end{array}$ & $\begin{array}{l}\text { Resumen } \\
\text { Este artículo discute la problemática de los valores } \\
\text { noticiosos y de los criterios de noticiabilidad } \\
\text { periodística en el marco más amplio de los valores } \\
\text { sociales, de las relaciones de poder y del telón } \\
\text { de fondo cultural que estructuran una sociedad. } \\
\text { Partimos de una concepcion del periodismo como } \\
\text { una actividad comunicacional que se distingue por } \\
\text { tres ejes: la relación con lo real; la naturaleza de su } \\
\text { producto - la información; su anclaje en el interés } \\
\text { público. Situamos las nociones de noticiabilidad } \\
\text { y de valores noticiosos en la articulación de estos } \\
\text { tres aspectos. Proponemos discutir estos conceptos } \\
\text { a partir de su vínculo en el campo de la vida y de } \\
\text { los valores sociales. Al final, exploramos estas } \\
\text { cuestiones empiricamente a través de un análisis del } \\
\text { tratamiento que a dado la revista brasilera "Veja" a la } \\
\text { conocida Operación "Lava Jato". } \\
\text { Palabras clave } \\
\text { Noticiabilidad. Valores sociales. Interés público. } \\
\text { Operación "Lava Jato". }\end{array}$ \\
\hline
\end{tabular}




\section{Expediente}

A revista E-Compós é a publicação científica em formato eletrônico da Associação Nacional dos Programas de Pós-Graduação em Comunicação (Compós). Lançada em 2004, tem como principal finalidade difundir a produção acadêmica de pesquisadores da área de Comunicação, inseridos em instituições do Brasil e do exterior.

\section{E-COMPÓS I www.e-compos.org.br I E-ISSN 1808-2599}

Revista da Associação Nacional dos Programas de Pós-Graduação em Comunicação. Brasília, v.20, n.3, set./dez. 2017. A identificação das edições, a partir de 2008 , passa a ser volume anual com três números. Indexada por Latindex I www.latindex.unam.mx

\section{CONSELHO EDITORIAL}

Ada Cristina Machado Silveira, Universidade Federal de Santa Maria, Brasil Alda Cristina Silva da Costa, Universidade Federal do Pará, Brasil Alfredo Luiz Paes de Oliveira Suppia, Universidade Estadual de Campinas, Brasil Ana Regina Barros Rego Leal, Universidade Federal do Piauí, Brasil Ana Carolina Rocha Pessôa Temer, Universidade Federal de Goiás, Brasil André Luiz Martins Lemos, Universidade Federal da Bahia, Brasil Angela Cristina Salgueiro Marques, Universidade Federal de Minas Gerais, Brasil Ângela Freire Prysthon, Universidade Federal de Pernambuco, Brasil Antonio Carlos Hohlfeldt, Pontifícia Universidade Católica do Rio Grande do Sul, Brasil Arthur Ituassu, Pontifícia Universidade Católica do Rio de Janeiro, Brasil

Bruno Campanella, Universidade Federal Fluminense, Brasil

Cláudio Novaes Pinto Coelho, Faculdade Cásper Líbero, Brasil Cárlida Emerim, Universidade Federal de Santa Catarina, Brasil Carlos Eduardo Franciscato, Universidade Federal de Sergipe, Brasil Danilo Rothberg, Universidade Estadual Paulista, Brasil Denise Tavares da Silva, Universidade Federal Fluminense, Brasil Diógenes Lycarião, Universidade Federal do Ceará, Brasil Eduardo Vicente, Universidade de São Paulo, Brasil Eliza Bachega Casadei, Escola Superior de Propaganda e Marketing - SP, Brasil Eneus Trindade, Universidade de São Paulo, Brasil

Erick Felinto de Oliveira, Universidade do Estado do Rio de Janeiro, Brasil Erly Vieira Júnior, Universidade Federal do Espírito Santo, Brasil Francisco de Assis, FIAM-FAAM Centro Universitário, Brasi

Francisco Elinaldo Teixeira, Universidade Estadual de Campinas, Brasil Francisco Gilson R. Pôrto Jr., Universidade Federal do Tocantins, Brasil Frederico de Mello Brandão Tavares, Universidade Federal de Ouro Preto, Brasil Gabriela Reinaldo, Universidade Federal do Ceará, Brasil Gilson Vieira Monteiro, Universidade Federal do Amazonas, Brasil Gustavo Daudt Fischer, Universidade do Vale do Rio dos Sinos, Brasil Itania Maria Mota Gomes, Universidade Federal da Bahia, Brasil Jiani Adriana Bonin, Universidade do Vale do Rio dos Sinos, Brasil José Afonso da Silva Junior, Universidade Federal de Pernambuco, Brasil José Luiz Aidar Prado, Pontifícia Universidade Católica de São Paulo, Brasi Josette Maria Monzani, Universidade Federal de São Carlos, Brasi Juçara Gorski Brittes, Universidade Federal de Ouro Preto, Brasil
Juliana Freire Gutmann, Universidade Federal da Bahia, Brasil Laura Loguercio Cánepa, Universidade Anhembi Morumbi, Brasil Leonel Azevedo de Aguiar, Pontifícia Universidade Católica do Rio de Janeiro, Brasil Letícia Cantarela Matheus, Universidade do Estado do Rio de Janeiro, Brasil Luciana Coutinho Souza, Universidade de Sorocaba, Brasil Maria Ataide Malcher, Universidade Federal do Pará, Brasil Maria Elisabete Antonioli, Escola Superior de Propaganda e Marketing - SP, Brasil Maria das Graças Pinto Coelho, Universidade Federal do Rio Grande do Norte, Brasil Marialva Carlos Barbosa, Universidade Federal do Rio de Janeiro, Brasil Marcel Vieira Barreto Silva, Universidade Federal da Paraíba, Brasil Marcia Tondato, Escola Superior de Propaganda e Marketing, Brasil Marli Santos, Universidade Metodista de São Paulo, Brasil

Márcio Souza Gonçalves, Universidade do Estado do Rio de Janeiro, Brasil Mauricio Mario Monteiro, Universidade Anhembi Morumbi, Brasil Mayka Castellano, Universidade Federal Fluminense, Brasil

Mozahir Salomão Bruck, Pontifícia Universidade Católica de Minas Gerais, Brasil Nisia Martins Rosario, Universidade Federal do Rio Grande do Sul, Brasil Paolo Demuru, Universidade Paulista, Brasil

Paula Melani Rocha, Universidade Estadual de Ponta Grossa, Brasil Potiguara Mendes Silveira Jr, Universidade Federal de Juiz de Fora, Brasil Priscila Ferreira Perazzo, Universidade Municipal de São Caetano do Sul, Brasil Rafael Cardoso Sampaio, Universidade Federal do Paraná, Brasil Rafael Tassi Teixeira, Universidade Tuiuti do Paraná, Brasil Regiane Lucas Garcês, Universidade Federal de Minas Gerais, Brasil Regiane Regina Ribeiro, Universidade Federal do Paraná, Brasil Renata Pitombo Cidreira, Universidade Federal do Recôncavo da Bahia, Brasil Renato Essenfelder, Escola Superior de Propaganda e Marketing, Brasil Roberto Elísio dos Santos, Universidade Municipal de São Caetano do Sul, Brasil Rodolfo Rorato Londero, Universidade Estadual de Londrina, Brasil Roseli Figaro, Universidade de São Paulo, Brasil

Simone Maria Andrade Pereira de Sá, Universidade Federal Fluminense, Brasil Sofia Cavalcanti Zanforlin, Universidade Católica de Brasília, Brasil Sônia Caldas Pessoa, Universidade Federal de Minas Gerais, Brasil Tatiana Oliveira Siciliano, Pontifícia Universidade Católica do Rio de Janeiro, Brasil Thaïs de Mendonça Jorge, Universidade de Brasília, Brasil

Valquiria Michela John, Universidade Federal do Paraná, Brasil

\section{CONSELHO CIENTÍFICO}

Cristiane Freitas Gutfreind, Pontifícia Universidade Católica do Rio Grande do Sul, Brasil | Eduardo Antônio de Jesus, Universidade Federal de Minhas Gerais, Brasil I Eduardo Morettin, Universidade de São Paulo, Brasil I Irene de Araújo Machado, Universidade de São Paulo, Brasil I Miriam de Souza Rossini, Universidade Federal do Rio Grande do Sul, Brasil

\section{COMISSÃO EDITORIAL}

Eduardo Antonio de Jesus, Universidade Federal de Minas Gerais, Brasil I Igor Pinto Sacramento, Universidade Federal do Rio de Janeiro, Brasil I Kelly Cristina de Souza Prudencio, Universidade Federal do Paraná, Brasil I Osmar Gonçalves dos Reis Filho, Universidade Federal do Ceará, Brasil I Rafael Grohmann, FIAMFAAM - Centro Universitário, Brasil (editor associado)

\section{CONSULTORES AD HOC}

Afonso de Albuquerque, Universidade Federal Fluminense, Brasil I Francisco Rüdiger, Pontifícia Universidade Católica do Rio Grande do Sul, Brasil I Gislene da Silva, Universidade Federal de Santa Cataria, Brasil I Luiz Cláudio Martino Universidade de Brasília, Brasil I Magali Nascimento Cunha, Universidade Metodista de São Paulo, Brasil I Márcia Franz Amaral, Universidade Federal de Santa Maria, Brasil I Tania Marcia Cezar Hoff, Escola Superior de Propaganda e Marketing, Brasil I Raquel Paiva, Universidade Federal do Rio de Janeiro, Brasil

\section{EQUIPE TÉCNICA}

ASSISTENTE EDITORIAL Márcio Zanetti Negrini I REVISÃO DE TEXTOS Melina Santos I EDITORAÇÃO ELETRÔNICA Roka Estúdio
COMPÓS I www.compos.org.br

Associação Nacional dos Programas de Pós-Graduação em Comunicação

Presidente

Marco Roxo

Programa de Pós-Graduação em Comunicação - UFF marcos-roxo@uol.com.br

Vice-Presidente

Isaltina Gomes

Programa de Pós-Graduação em Comunicação - UFPE isaltina@gmail.com

Secretária-Geral

Gisela Castro

Programa de Pós-Graduação em Comunicação

e Práticas de Consumo - ESPM

castro.gisela@gmail.com

CONTATO I revistaecompos@gmail.com 